\title{
O tempo de trabalho: uma chave analítica
}

Henrique Amorim*

Resumo: O tempo de trabalho é uma noção central para a análise marxista da sociedade capitalista. De Karl Marx aos nossos dias, a discussão sobre a redução do tempo de trabalho ganhou várias interpretações. Entre elas está aquela que aponta para a progressiva redução do tempo de trabalho. Progressiva, nesse caso, não é entendida com base em sua própria contradição, isto é, como uma necessidade do capital para sua valorização, mas sim como um processo de redução crescente do tempo do trabalho que no limite colocaria a relação de capital em xeque. A partir dessa interpretação, a tendência de redução do tempo de trabalho anunciaria à extinção das relações de produção capitalistas. Estaríamos, com isso, diante de uma perspectiva que se fundamenta em um automatismo social e, portanto, que pressupõe o fim do capitalismo de maneira determinista. Retomando as implicações mais centrais que a reestruturação produtiva, chamada de toyotista, proporcionou, sobretudo aquelas relativas à substituição massiva de trabalhadores por tecnologia informacionais e microeletrônicas, temos como objetivo desse artigo revisitar a noção de tempo de trabalho, tentando, com isso, demonstrar a fragilidade das teses que pressupõe um esgotamento estrutural da sociedade capitalista como fruto de um automatismo do movimento interno de reprodução do capital. Concluímos que estas teses, na prática, mistificam o papel central da luta de classes, primeiro, como elemento determinante do processo de constituição das forças produtivas capitalistas e, segundo, para a superação da subalternidade do trabalho em relação ao capital.

Palavras-chave: tempo de trabalho, automatismo social, pós-grande indústria, trabalho produtivo, trabalho improdutivo, valor-trabalho.

\section{Introdução}

A discussão sobre o tempo de trabalho apresenta-se como um dos eixos analíticos centrais para a fundamentação da teoria do valor-trabalho. É com base nesse eixo que Karl Marx observa a importância e a histórica necessidade de expansão do capital como uma relação social que visa à abertura contínua de novas fronteiras, estejam elas dentro do processo de produção estrito senso, onde se articulam estratégias para o aumento da produtividade, com diminuição do tempo de trabalho, estejam elas vinculadas a estratégias que envolvam reconfigurações espaciais regionais, nacionais e internacionais da lógica da produção capitalista. A valorização do capital, com isso, absorve e, ao mesmo tempo, descarta novos continentes improdutivos de trabalho e essa absorção passa pelo redimensionamento da utilização do tempo de trabalho (Marx, 1988; 2011). Não obstante, como se fundamentaria essa absorção do tempo de trabalho? Ela teria uma dimensão lógica no sentido em que opera de forma relativamente autônoma em relação aos interesses de classe? Ou esse tempo gasto na produção teria em si uma dinâmica política e determinada pela luta de classes?

\author{
* Professor de \\ sociologia do \\ Departamento de \\ Ciências Sociais e \\ do Programa de \\ Pós-Graduação em \\ Ciências Sociais da \\ Unifesp. E-mail: \\ henriqueamorim@ \\ hotmail.com. \\ Esse trabalho é \\ fruto de pesquisa \\ desenvolvida com o \\ apoio da Fapesp e \\ do CNPq.
}


1. Para uma análise crítica dos automatismos sociais, cf.: Vincent (1993). Entre os autores que vislumbraram a transformação social com base em um automatismo econômico e ou tecnológico, cf., entre outros: Schaff (1992) e Lojkine (1992). Entre aqueles que apontam para a não centralidade do trabalho nas sociedades contemporâneas, cf., entre outros: Gorz (1987); Offe (1989) e Habermas (1987).
Nesse processo de valorização no qual o capital tem como fundamento de sua sobrevivência a expansão, o tempo de trabalho apresenta-se de maneira contraditória. Ao mesmo tempo em que a valorização do capital funciona no sentido de ampliar as fronteiras necessárias para reproduzir o capital como relação social hegemônica, se manifesta a diminuição do tempo de trabalho na produção e, como consequência, a diminuição do trabalho vivo dentro dos processos de trabalho.

Esta contradição social, constitutiva do modo de produção capitalista, gerou inúmeras celeumas entre autores marxistas e não marxistas. A que nos interessa nesse artigo é aquela que, com base na tendência de dispensabilidade do trabalho vivo, qualifica a transformação e a superação da sociedade capitalista, como um processo automático. A tese se resume no entendimento de que o próprio modo de produção capitalista chegaria a um limite de dispensabilidade do tempo de trabalho (de trabalho vivo) que o tornaria secundário ou mesmo supérfluo. A libertação das amarras do capital seria apresentada, portanto, não como fruto de embates, lutas e confrontos entre classes sociais, mas com base em um automatismo social que se desenvolveria no interior do próprio capitalismo. ${ }^{1}$

Essa interpretação nos remete diretamente aos Grundrisse (2011), texto escrito por Marx entre 1857 e 1858, onde o autor, entre tantas outras questões, estuda a forma valor, por vezes desdobrando-a em um exercício lógico. Uma de suas indicações centrais é a de que haveria um distanciamento do processo de valorização do capital de sua base material. Nesse exercício lógico, Marx faz parecer que esse distanciamento se tornaria, em algum momento, absoluto e, de certa forma, libertaria o trabalho vivo da exploração e da dominação do capital. No entanto, como podemos observar em O capital (1988 [1867]), e mesmo em outras passagens dos Grundrisse, esse distanciamento não pode ser levado ao limite pelo capital, tendo em conta que esse "levar ao limite" implicaria na própria dissolução voluntária do capital como relação social hegemônica.

A relação entre capital e trabalho apresenta-se, diversamente, como uma contradição em processo. Os capitalistas obstinam-se em reduzir ao máximo o trabalho necessário, fonte de criação de toda a riqueza, mas não podem se desprender dele por completo. Ao mesmo tempo em que os interesses capitalistas de obtenção de lucro têm na exploração do trabalho sua fonte de valor, anseiam, com o objetivo de baratear a força de trabalho, reduzir o tempo de trabalho a um mínimo. Se, por um lado, os interesses capitalistas tendem a reduzir a presença do trabalho para melhor controlá-lo e barateá-lo, por outro, a utilização do trabalho vivo é indispensável para a produção de mais-valia. Além disso, essa redução não se dá de forma uniforme e homogênea nas sociedades capitalistas contemporâneas. O fluxo de capitais permite que em determinados países haja uma redução da participação do trabalho vivo dentro dos processos 
de produção de mercadorias, ao mesmo tempo em que em outros países a utilização da força de trabalho aumenta vertiginosamente, garantindo a manutenção de taxas de lucro elevadas.

Nos últimos 40 anos, essa contradição típica da sociedade capitalista, foi apontada como superada. Com as transformações produtivas e políticas dos anos 1960 e 1970 nos países de economia central, vislumbrou-se o início de uma nova era: pós-industrial, pós-materialista, da informação, das atividades intelectuais, do conhecimento, de serviços e, por fim, cognitiva. ${ }^{2}$ Essa nova era estaria supostamente fundada em uma sociabilidade não mais determinada pela produção tipicamente capitalista. Superar-se-ia, portanto, a contradição entre a exploração do tempo de trabalho e sua dispensabilidade ou, pelo menos, essa contradição não seria mais central.

Ao revisarem os Grundrisse, os autores que fundamentam o trabalho imaterial como força produtiva central e, por conseguinte, caracterizam as sociedades contemporâneas como cognitivas, ${ }^{3}$ assentam suas teses em uma leitura do manuscrito de Marx, procurando justificar o surgimento de interstícios de libertação social dentro do próprio capitalismo contemporâneo. ${ }^{4}$ Nesse sentido, procuram justificar o surgimento do capitalismo cognitivo como um movimento automático do próprio capitalismo industrial, isto é, como um percurso, um desdobramento lógico que teria sido anunciado, já no século XIX, pelo próprio MarX.

No sentido de contestar essa interpretação, retomaremos algumas teses de Marx dos Grundrisse e de $O$ capital com o objetivo de problematizar os limites do processo de valorização e acumulação capitalistas, sobretudo os limites que se constituem como elementos materiais para a superação da sociedade capitalista e, portanto, de libertação do trabalho em relação ao capital. O norte teórico desse artigo assenta-se, assim, em torno da crítica às concepções que se baseiam em uma interpretação determinista da história. Nesse sentido, nos remeteremos, primeiramente, à discussão sobre a pós-grande indústria, elemento chave de muitas divergências sobre a fase atual do capitalismo contemporâneo. Em segundo lugar, serão tratadas as questões relativas à relação entre trabalho produtivo e o trabalho improdutivo, o que, de certa forma, pode trazer elementos analíticos significativos para a crítica da tese de uma sociedade fundamentalmente baseada nos serviços. Por fim, retomaremos os pontos centrais sobre o tempo de trabalho, observando, com base em Marx, como se fundamenta a relação entre tempo livre/tempo liberado e tempo de trabalho, ou seja, procuraremos identificar como o tempo dispensado no capitalismo tem uma fundamentação negativa para os coletivos de trabalho, não sendo possível a constituição de "espaços de libertação" dentro do próprio capitalismo.
2. Sobre a sociedade pós-industrial e do conhecimento cf.: Bell (1973) e Touraine (1970); sobre a sociedade pós-materialista, cf. Inglehart (1997); sobre a sociedade da informação, cf.: Castells (1999) e Melucci (1980); sobre a sociedade baseada nas atividades intelectuais, cf: Gouldner (1979); sobre a sociedade de serviços, cf.: Offe (1989a); Touraine (1989); e sobre a sociedade cognitiva ou capitalismo cognitivo, cf.: Negri (2003), Gorz (2005), e Moulier-Boutang (2007).

3. Há muitos autores que desenvolvem a tese do capitalismo cognitivo. No entanto, os autores mais expressivos são Moulier-Boutang (2007) e toda a tradição que se fundamenta em Negri (2003) e Negri e Hardt (2001); além das teses de Gorz (2005) sobre o imaterial.

4. Como nos indicada Nicolas-Le Strat (1996: 103): segundo Gorz, "[...] Nos interstícios da produção, os indivíduos, redescobririam aquilo que daria a qualidade de sua existência dos valores não imediatamente quantificáveis, do tempo livre de cálculo e do rendimento, de uma autoapropriação das 
causas de sua ação, dos compromissos voluntários e reflexivos... até a [...] esfera da integração social." Com esse mesmo mote, Gorz (1987) fundamentou uma sociedade dual composta por uma parte heterônoma e outra autônoma e também esferas sociais, em Habermas (1987), como as do sistema e do mundo da vida.

\section{A pós-grande indústria}

A discussão sobre a pós-grande indústria desenvolveu-se nas últimas décadas a partir de um resgate de passagens dos Grundrisse sobre o desenvolvimento do capital constante. A relação pressuposta nesse debate tem como horizonte um processo de subordinação do trabalho ao capital que em seu percurso teve desdobramentos chegando à forma atual da subordinação formal-intelectual. O processo de redução do tempo de trabalho para o aumento de produtividade teria, em termos lógicos, chegado a uma fronteira em que a contradição entre diminuição do tempo de trabalho e centralidade do trabalho abstrato teria chegado ao fim. A tese de fundo que explicita esse raciocínio é de que a incorporação do trabalho intelectual ao processo de produção teria reintroduzindo o trabalho e o trabalhador como sujeitos desse processo. Agora, o capital precisaria, necessariamente, do trabalho intelectual e, portanto, teria se colocado um problema sem solução.

Ao indicar uma terceira forma da indústria, Fausto (1989), por exemplo, concebe esse momento do desenvolvimento industrial, remetendo-o ao surgimento de uma nova sociedade. As formas de subordinação do trabalho em relação ao capital foram no passado, para Fausto, expressão de subsunções. A manufatura se fundamentou na subordinação formal e a maquinaria na subordinação real (formal e material) do trabalho em relação ao capital. Com o advento da pós-grande indústria se fundamentaria uma terceira forma na medida em que o "[...] homem não é mais sujeito do processo de produção. [...] O homem é de certo modo 'posto para fora', liberado do processo, mas é assim mesmo que ele passa a dominar o processo" (1989: 52).

A última reestruturação da produção, com base no desenvolvimento da automação, teria constituído, dessa forma, uma nova condição de subordinação que superaria a subordinação real do trabalho ao capital na medida em que colocaria como centro da produção o caráter subjetivo do trabalho. Em resumo, a subordinação real (formal e material) daria lugar à subordinação formal-intelectual do trabalho ao capital. "O autômato [diz Fausto] é agora autômato espiritual, não simples autômato 'vivo'” (1989: 58-59). Nesse sentido, haveria, para o autor, uma reconfiguração na produção que criaria a possibilidade de retomada do domínio do processo de trabalho pelo trabalhador. Citando Marx dos Grundrisse, indica que "[...] assim, o capital que era uma alma apetitiva [...] de trabalho alheio [...] se apossa de um intelecto, mas acaba sendo dominado por ele" (1989: 59). Pressupõe-se, assim, que a nova forma de subordinação formal-intelectual não seria mais adequada logicamente ao padrão de valorização do capital, isto é, o capital teria criado um problema que ele mesmo não conseguiria resolver. O trabalhador passaria, nestes termos, de mediador a sujeito do processo de trabalho, tornando a subjetividade um elemento central, já que ela seria utilizada durante o processo de produção. Isso, para Fausto, requalifica a utilização do tempo de trabalho para a produção de valor. 
A valorização não é mais a cristalização de um tempo posto. Ela se dá no tempo. De certo modo, o tempo volta à sua imediatidade. A "valorização" se liberta do tempo de trabalho, mas com isto ela não será mais valorização (Fausto, 1989: 50).

Parece, assim, haver uma contradição no raciocínio de Fausto. Ao mesmo tempo em que o autor vislumbra uma nova fase da produção capitalista, fundamentada pela subordinação formal-intelectual e marcada pela recondução do trabalho a elemento ativo do processo de produção, indica que a valorização teria chegado ao fim. De um lado, a produção capitalista se preserva reintroduzindo o trabalho ao processo de produção. De outro, ainda opera como uma forma de subordinação do trabalho ao capital.

Seguindo a análise de Fausto, Prado (2004) indica a pós-grande indústria como uma fase do desenvolvimento da produção industrial que não estaria completamente estruturada pela dependência em relação ao tempo de trabalho. Uma produção social, em certo sentido alheia ao tempo de trabalho, seria utilizada durante o tempo de trabalho. Assim, a pós-grande indústria é apresentada como a última fase da produção capitalista, fase na qual a ciência e a tecnologia seriam os fundamentos de valorização do capital, através do trabalho criativo, inteligente, cognoscitivo. ${ }^{5} \mathrm{~A}$ busca desenfreada pela diminuição de tempo de trabalho não estaria mais no norte da produção de mercadorias; primeiro porque a produção, na pós-grande indústria, seria de caráter heterogêneo em oposição à produção homogeneizada da grande indústria; segundo, porque, com a mudança dessa propriedade particular, a produção se tornaria qualitativa em oposição à produção quantitativa da grande indústria. Com isso, Prado observa a radical diferença entre uma produção baseada no tempo de trabalho, sintetizada na forma da grande indústria e fundamentada na quantidade e na produtividade em oposição à produção não mais baseada no tempo de trabalho, sintetizada na pós-grande indústria e fundamentada pela qualidade. Assim, "[...] dada a relativa irrelevância do tempo de trabalho e a proeminência da qualidade desse tempo, a ciência e a tecnologia atuam na produção do valor por meio de trabalho" (Prado, 2004: 64). De nosso ponto de vista, a análise sobre a pós-grande indústria tem necessariamente que se submeter ao processo histórico. Podemos observar hoje que, com o processo de automação das indústrias, altas taxas de produtividade do trabalho ainda imperam. ${ }^{6}$ Quantidades muito grandes de mercadoria são produzidas na medida em que se reproduz, radicalizando a lógica da grande indústria, o emprego da ciência e da tecnologia à produção, com vistas, sobretudo, à economia de tempo de trabalho. Nesse sentido, a análise de Fausto parece presa à lógica formalista do processo histórico, isto é, a ordem lógica submete a ordem histórica, valorizando, nesta última, aspectos que são fruto de desdobramentos conceituais e não tem efetiva concretude se os pensarmos dentro da atual divisão internacional do trabalho e do quadro de exploração do trabalho em empresas capitalista contemporâneas.
5. Para Prado, a base material para a constituição do socialismo já estaria dada no sentido em que o tempo de trabalho não mais se fundamenta como elemento quantitativo do processo de valorização do capital, visto que a ciência e a tecnologia, por meio do trabalho, teria se tornado a base qualitativa do processo de produção. Em suas palavras: "Ainda que por um caminho que se afasta do legado de Marx, certas conclusões de Gorz mostramse corretas. O seu ponto principal é que 'o capitalismo chamado de cognitivo' - e por isso deve se entender que este modo produção entrou já numa fase em que o conhecimento se torna mais e mais o principal conteúdo do capital - 'é já a crise do capitalismo'. Pois a economia baseada no trabalho conceitual e no conhecimento científico e tecnológico avançado é incongruente com a relação de capital" (Prado, 2004: 53). Bastaria, portanto, "[...] a abolição da relação social de capital e também do trabalho assalariado" já que a base material teria todas as condições necessárias para superar a forma valor. Apesar 
de sublinhar, no início de seu texto, a necessidade "[...] da ação dos homens" (idem: 46) no processo de superação do modo de produção capitalista, Prado parece admitir que a base material para essa superação já estaria constituída hoje com a pósgrande indústria e que esta base não tem relação direta com a "ação dos homens".

\section{Há inúmeros} exemplos de intensificação e superexploração do trabalho, além de trabalho escravo e semiescravo no Brasil, na China e em outros países centrais à economia capitalista que qualificam a radicalização dos preceitos tayloristas e fordistas para a exploração da força de trabalho física (manual) e imaterial (intelectual) e que, em consequência, desabonam qualquer validade das teses sobre o fim da produção industrial e da estruturação de sociedades centradas no não trabalho. Entre tantas outras importantes referências sobre as novas e "velhas" configurações do trabalho no capitalismo contemporâneo, Cf.: as compilações de Dal Rosso (2008); Dal Rosso e Fortes (2008); e Antunes (2006; 2013). Além dos textos sobre o trabalho escravo de Sakamoto (2004;
A pós-grande indústria, como última fase da produção do valor, só tem sentido conceitual em Marx, seja nos Grundrisse, seja em O capital, se a qualificamos dentro de uma análise histórica e determinada pela luta de classes. Não se trata, como vislumbra Fausto, de uma fase do capitalismo que de forma automática negaria a própria lógica capitalista. A pós-grande indústria não se fundamenta como uma negação da negação, tendo em vista que está diretamente submetida às formas de obtenção de lucro. A autorruptura sem lutas e sem classes, ademais, não se fundamenta como uma tese que tem seu berço em Marx. Para Marx, a última fase do valor tem relação direta com o fim das classes sociais e, portanto, com a necessidade de uma direção socialista que alce o "fim do valor-trabalho" como seu objetivo central. Para esses autores, a luta de classes, portanto, torna-se um elemento chave do processo de abolição do trabalho assalariado e do capital apenas depois da constituição da pós-grande indústria como base do novo modo de produção. Antes disso, a luta, elemento central da análise marxiana, é secundarizada em relação ao movimento espontâneo da economia, impulsionado, sobretudo, pelo desenvolvimento aparentemente autônomo das forças produtivas.

A "evolução do sistema" não leva, portanto, à autorruptura. Para Marx, essa ruptura só pode ser síntese de embates classistas e está vinculada à constituição de forças sociais revolucionárias. Os elementos constituintes de uma possível ruptura se articulam, não obstante, entre as relações de produção e as forças produtivas, sendo estas resultados/sínteses do confronto entre trabalhadores e capitalistas em formações sociais historicamente determinadas. Não há, nesse sentido, uma determinação interna ao movimento de extração de mais-valia que faça implodir automaticamente o modo de produção capitalista. Esta pressuposição, além de determinista, considera a tendência de desenvolvimento das forças produtivas isolando-a de seu elemento transformador central: a luta.

Não obstante, é preciso também levar em consideração os movimentos e as tendências próprios do modo de produção capitalista. Se, por um lado, Marx indica manifestações tendenciais e internas ao processo de valorização do capital, por outro, demonstra como estas tendências devem ser entendidas historicamente na medida em que "sofrem" a influência de contratendências. Nesse sentido, as tendências degenerativas do processo de valorização como, por exemplo, a de tendência de queda da taxa de lucro, é apreendida por Marx como uma contradição em processo que, em última análise, não opera automaticamente, mas dentro de historicidades específicas e devem ser observadas conjunturalmente. 
As transformações na produção ocasionadas nas últimas quatro décadas podem ser analisadas com base na relação entre tempo de trabalho e tempo livre. No entanto, parece-nos de início importante questionar: haveria uma transformação estrutural na produção que teria alterado os fundamentos da produção de mercadorias com o objetivo de produzir mais-valia? Parece-nos que esse questionamento está diretamente relacionado à compreensão do trabalho produtivo e do trabalho improdutivo e, particularmente, dos serviços e de seu crescimento nas sociedades capitalistas contemporâneas.

Marx afirma, no Capítulo VI - Inédito (1985) que o objetivo central do capital e seu fim imediato é a produção de mais-valia. Nesse sentido, produtivo seria todo aquele empreendimento capitalista que tem por objetivo produzir diretamente mais-valia, isto é, "[...] só aquele trabalho que seja consumido diretamente no processo de produção com vista à valorização do capital" (1985: 108). Assim, a designação de produtivo em Marx deve sempre relacionar-se ao processo geral de produção, isto é, na relação entre processo de trabalho e processo de valorização, na qual o processo de trabalho está subordinado aos "interesses" do processo de valorização. Portanto, trabalho produtivo vem a ser aquele trabalho que é utilizado, de maneira socialmente combinada, como instrumento direto do capital para sua valorização.

O processo de produção é, então, compreendido por Marx como uma combinação de relações sociais que operam em variadas frentes. Incorporam-se, por um lado, trabalhos predominantemente manuais articulados a trabalhos predominantemente intelectuais ou cognitivos, sempre com o objetivo de incrementar a produção na medida em que uma maior quantidade de funções seja controlada pelo capital. O que vale para o capital não é, então, uma determinada forma de trabalho, como nos indica Braverman, mas

[...] se foi obtido na rede de relações sociais capitalistas, se o trabalhador que o executa foi transformado em homem pago e se o trabalho assim feito foi transformado em trabalho que produz lucro para o capital (1980: 305).

Na prática, o capital submete uma quantidade sempre maior de funções e profissões distintas para atingir a finalidade de produzir mais-valor.

[...] este como diretor (manager), engenheiro (engineer), técnico e etc., aquele como capataz (overlooker), aquele outro como operário manual ou até como simples servente [...] são cada vez em maior 
número as funções da capacidade de trabalho incluídas no conceito imediato de trabalho produtivo, diretamente explorados pelo capital e subordinados em geral ao seu processo de valorização e de produção (Marx, 1985: 110).

Ao analisar os serviços, o que desde início deve ser diferenciado da produção de serviços, isto é, a produção de mercadorias na forma tipicamente capitalista produtora de mais-valia, vemos que não há uma troca de tempo de trabalho por dinheiro, como representação do valor. Troca-se dinheiro, na forma de rendimento, por um serviço, isto é, o dinheiro trocado não entra no ciclo da produção como capital. Funciona, assim, como indica Marx, como meio de circulação e não como capital.

A diferença entre o trabalho produtivo e o improdutivo consiste apenas em que, em si, o trabalho é trocado por dinheiro como dinheiro e em dinheiro como capital. Sempre que compro uma mercadoria a um trabalhador, como, por exemplo, no caso do trabalhador independente, do artesão (self employing labourer, artisan) etc., a categoria (trabalho) está totalmente fora de questão porque não se dá um intercâmbio direto entre o dinheiro e o trabalho de qualquer índole, mas sim, entre dinheiro e mercadoria (Marx, 1985: 119).

Para retomar a perspectiva que caracteriza o capitalismo dentro de uma tendência de redução do tempo de trabalho, isto é, do trabalho produtivo, como um dos elementos centrais para a manutenção da reprodução da vida burguesa, Marx vislumbra o crescimento do setor de serviços em detrimento do setor produtivo e a substituição do trabalho produtivo por trabalho improdutivo. Não obstante, o autor diferencia, em alguns pontos, o trabalho produtivo daquele que denomina de imaterial ou não material.

Essa diferenciação é importante na medida em que, no debate contemporâneo sobre a imaterialidade do trabalho, a tese que proclama o "capitalismo cognitivo" tem como eixo central o argumento de que o trabalho imaterial ou cognitivo seria a força produtiva central, ou pelo menos, se apresentaria tendencialmente como, nas sociedades atuais. Na compreensão de Gorz (2005), Moulier-Boutang (2007), Viveret (2003), entre outros, a forma valor estaria em crise pois o conhecimento, fundamento do trabalho imaterial, dificulta a formalização do valor, isto é, na medida em que o conhecimento não poderia ser medido por unidades de tempo de trabalho. Citando Marx dos Grundrisse, Gorz assevera:

[...] "o trabalho em sua forma imediata", mensurável e quantificável, deverá, por consequência, deixar de ser a medida da riqueza criada. Esta "dependerá cada vez menos do tempo de trabalho e da quantia de trabalho fornecida"; ela dependerá cada vez mais "do nível geral da ciência e do progresso da tecnologia" (2005: 15-16). 
O autor, conclui, por conseguinte, que o desenvolvimento das forças produtivas capitalistas imateriais teria colocado a própria forma valor e, por conseguinte, o capital em xeque.

A questão aqui não se fundamenta se Marx está ou não correto em tal afirmação. A questão que nos parece fundamental é: Marx se refere a qual sociedade quando pressupõe as possibilidades de libertação do tempo de trabalho pela introdução massiva de ciência e tecnologia? A resposta de Gorz, ao se utilizar dessa passagem, é obvia: Marx se referiria ao último estágio da produção capitalista. Contrariamente, entendemos que essa possibilidade só pode ser vislumbrada em uma sociedade socialista, na qual todas as forças sociais estejam empenhadas para desenvolver tal substituição e ao mesmo tempo libertar o trabalho de sua subordinação capitalista.

Gorz, não obstante, entende que o modo de produção comunista já se apresentaria nos interstícios da sociedade capitalista. Um exemplo disso seriam as ferramentas informacionais e a possibilidade de apropriação coletiva do espaço virtual, sobretudo demonstradas pela constituição de softwares livres. A instauração de uma

[...] comunidade virtual, virtualmente universal, dos usuários-produtores de programas de computador e de redes livres, instaura relações sociais que esboçam uma negação prática das relações sociais capitalistas (2005: 66).

Essas relações de "cooperação voluntária", segundo Gorz, conviveriam com o modo de produção capitalista, seriam práticas não mensuráveis e não subordinadas à lógica da valorização do capital. Seriam, por fim, antagônicas às práticas capitalistas na medida em que "[...] o capitalismo do saber gera em si e para além de si a perspectiva de sua possível supressão. Em seu âmago [aponta Gorz] germina uma semente comunista" (idem: 69).

Uma observação crítica permite retomar a discussão sobre o trabalho produtivo e o trabalho improdutivo. A afirmação de que o trabalho imaterial é a força produtiva central nas sociedades contemporâneas está assentada no argumento de que o conhecimento e a informação são elementos não quantificáveis e não redutíveis a unidades de tempo de trabalho. No entanto, a não conversibilidade do trabalho imaterial em valor está fundamentada em seu caráter não tangível, isto é, para Gorz, o conhecimento e a informação são elementos que não apresentam fisicidade e, portanto, não poderiam ser codificados.

Há, com isso, uma incompreensão em relação à teoria do valor-trabalho de Marx. Não são, nestes termos, os conteúdos materiais (físicos) ou imateriais (não físicos) que determinam, na visão de Marx, o caráter produtivo ou não do trabalho. ${ }^{7}$ As mercadorias
7. Marx, afirma nesse sentido que: "Para o empresário da fábrica de conhecimentos os docentes podem ser meros assalariados" (1985: 120) 
são consideradas como depositárias de relações sociais específicas (tipicamente ou não capitalistas). O que dá sentido à matéria (histórica), contrariamente, é o conjunto de relações sociais que tem por objetivo valorizar o capital, sintetizando-se como mercadoria. Determinar um encontro, uma síntese de relações sociais como produtiva não passa necessariamente pela fisicidade do produto, mas exatamente pelo modo, pela maneira ou forma como esse conjunto de relações se sintetizou. Portanto, a materialidade das relações sociais, do ponto de vista da análise marxiana, não está ligada à fisicidade das mercadorias. Ela está relacionada, na verdade, diretamente à materialidade histórica de seu modo de produzir.

\section{Tempo de trabalho e tempo livre}

O tempo de trabalho necessário à produção e à manutenção da reprodução social nos remete, com base na análise de Marx, à forma histórica do funcionamento do capitalismo. Essa forma histórica tem um prazo de validade, ou seja, é histórica, mas não têm uma data de expiração determinada pressuposta. Marx observa essa tendência contraditória nos Grundrisse sob dois ângulos complementares. De um lado, a potência do capital em expandir-se e, de outro, os limites históricos dessa expansão que abririam espaço para crises, lutas, embates que possibilitem a superação da sociedade capitalista.

O esforço teórico de Marx em levar essa contradição social ao limite tem como consequência o desenvolvimento conceitual da redução do tempo de trabalho ao ponto em que este esteja totalmente ou, pelo menos, de maneira hegemônica, subordinado ao tempo livre. Entretanto, é importante nos interrogarmos: o limite do capital, indicado por Marx nos Grundrisse, seria um limite criado por forças sociais antagônicas, isto é, pelas classes sociais, ou seria ocasionado por uma determinação intrínseca ao desenvolvimento do capital? "[...] O capitalismo teria um fim automático, resultante de tendências internas degenerativas, ou precisaria ser derrubado por forças sociais revolucionárias?" (Miglioli, 1994: 62). Isto é, o capital estaria fadado, em um processo automático, a um fim, ou a análise sobre o desenvolvimento das relações de subsunção nos Grundrisse seria um exercício lógico que pressuporia necessariamente a luta de classes? Marx problematiza essa questão argumentando que:

[...] se não encontrássemos veladas na sociedade, tal como ela é, as condições materiais de produção e as correspondentes relações de intercâmbio para uma sociedade sem classes, todas as tentativas para explodi-la seriam quixotadas (2011: 107).

No entanto, quais seriam as condições materiais para revolução da sociedade capitalista? A questão sobre o tempo de trabalho - elemento de nossa análise - contribui 
mais uma vez para explicitarmos essa questão, sobretudo no momento em que temos a intenção de desqualificar qualquer perspectiva sobre a formação do valor que esteja pautada em uma mensuração aritmética e econométrica. ${ }^{8}$

Para entendermos o exercício lógico que Marx fez nos Grundrisse, exercício que retira do palco, temporariamente, a luta de classes, primeiramente devemos passar pela designação de que o tempo de trabalho é medida do valor e, por isso, não tem um valor em si mesmo. Sendo medida, deve abstrair-se de qualquer forma de quantificação. A quantificação, na verdade, deve ser pensada na relação entre os valores de troca produzidos em um tempo social médio despendido na produção, sempre considerando um estágio histórico do desenvolvimento das forças produtivas. Se a tendência geral é inserir novas formas de ciência e tecnologias produtivas para diminuir o tempo de trabalho, barateando o valor da força de trabalho, a liberação de tempo de trabalho caminharia sempre para o infinito.

O exercício lógico de Marx nos Grundrisse desenvolve-se apenas na primeira parte dessa relação, isto é, na incorporação de novas forças produtivas ao processo de produção, sem, nesse momento, questionar-se sobre as consequências dessa liberação de tempo de trabalho para a classe trabalhadora. Dessa forma, Marx indica relações sociais necessárias ao processo de liberação de tempo de trabalho com o objetivo de revolucionar as relações sociais capitalistas, superando as determinações da "lei" do valor-trabalho. A primeira seria um alto nível de produtividade e de relativa abundância e a segunda seria a necessidade de uma população excedente, como também de uma produção excedente.

A criação de tempo disponível teria assim relação direta com a criação de tempo de não trabalho, ou seja, redução de tempo de trabalho necessário. Na busca incessante de crescimento, o capital acabaria, malgré lui, ${ }^{9}$ por ser instrumento, em escala social, da criação de tempo disponível ao reduzir o tempo de trabalho "[...] a um mínimo decrescente e, com isso, na transformação do tempo de todos em um tempo livre para seu próprio desenvolvimento" (Marx, 20011: 590). No entanto, como já salientamos, essa redução de tempo de trabalho não pode ser levada ao limite na medida em que as forças sociais capitalistas não podem desvencilhar-se completamente do trabalho. O capital cria, dessa forma, mais tempo de mais-trabalho. ${ }^{10}$

Marx - sempre nos Grundrisse - indica por extensão que esse crescimento volumoso das forças produtivas não poderia mais estar ligado à apropriação de sobretrabalho e que a massa operária deveria apropriar-se de seu mais-trabalho. Com isso, o tempo necessário como medida do trabalho deixaria de existir e o tempo disponível passaria a ser o centro de constituição da nova sociabilidade. Já que a riqueza real é produto de uma força produtiva social,
8. Como sugere Husson (2000: 2): “A ideia que o capital aproveita da faculdade de se apropriar dos progressos da ciência (ou do conhecimento) não é uma ideia nova, já que é um elemento fundamental de análise marxista do capitalismo. Pretender que se trate de uma descoberta recente e de uma real novidade faz retornar a uma compreensão estreita da teoria marxista do valor conduzida a um simples cálculo do tempo de trabalho".

9. Expressão francesa empregada por Marx nos Grundrisse/Borrador (1972: 232), em português "apesar dele".

10. Para Tosel (1994), o tempo liberado pela redução de tempo de trabalho produtivo não implica no desenvolvimento do indivíduo social, nos moldes anunciados por Marx nos Grundrisse. Segundo o autor, esse tempo liberado não é tempo livre, já que é negativamente liberado na forma do desemprego, da precarização, do subemprego, do banco de horas etc. fundamentando assim a impossibilidade efetiva de a classe trabalhadora usufruir desse "tempo liberado". 
[...] então, por um lado, o tempo de trabalho terá sua medida nas necessidades do indivíduo social, por outro, o desenvolvimento da força produtiva social crescerá com tanta rapidez que, embora a produção seja agora calculada com base na riqueza de todos, cresce "o tempo disponível" de todos (Marx, 2011: 591).

Nestes termos, o tempo de trabalho deixaria de ser medida de valor, sobretudo no momento em que Marx vislumbra a transformação massiva do trabalhador oprimido pelo ritmo industrial de trabalho em trabalhador exercendo uma atividade de vigilância e regulação do processo de trabalho.

Esse exercício lógico-conceitual que Marx fez nos Grundrisse, não obstante, deve ser apreciado com base em suas análises fundamentalmente políticas. O fim da lei do valor em Marx não pode ser examinado sem a consideração de que as forças sociais presentes na sociedade capitalista e na sociedade de transição socialista se empenhem para essa finalidade. Qualquer automatismo social está decididamente descartado da análise marxiana, visto que o próprio autor, em muitas de suas obras, destacou o lugar central da luta de classes na constituição de uma nova sociedade emancipada do capital. É com esse sentido que encaminho minhas considerações finais.

\section{Considerações finais}

O capital, nas últimas décadas, ao contrário de estruturar uma autorruptura e propiciar qualquer forma de libertação da classe trabalhadora de suas amarras, manifestou uma monstruosa capacidade em recompor suas bases de dominação e exploração. Ao fundamentar-se na reestruturação da produção e em políticas neoliberais, fez aumentar suas taxas de lucro através de um processo de subalternização da classe trabalhadora nunca antes visto. Esse processo de reconfiguração das bases de exploração capitalista criou, em contraposição às teses que fundamentam o capitalismo cognitivo, um cenário amplamente desfavorável para a classe trabalhadora.

Perda de direitos trabalhistas, terceirização e precarização do trabalho, superexploração e intensificação da produção, codificação das formas de trabalho intelectual, autogerenciamento das tarefas produtivas, além de trabalhos com contratos temporários e do trabalho escravo e semiescravo são formas utilizadas pelo capital para reorganizar o padrão taylor-fordista de produção, acrescentando-Ihe formas "primitivas" de exploração e dominação. ${ }^{11}$ Não obstante as manifestas condições em que a classe trabalhadora mundial se vê condicionada, alguns autores insistem na tese segundo a qual haveria, no processo de redução do tempo de trabalho, a possibilidade de constituição de espaços de liberdade alheios à produção e racionalização da economia capitalista. 
Notamos que a redução do tempo de trabalho reproduzida socialmente pela substituição de trabalho vivo por trabalho morto, com a incorporação da ciência e da tecnologia, está qualificada por um insistente objetivo produtivo: a manutenção da sociedade capitalista e das classes sociais que a constituem. Não há elementos essencialmente neutros ou positivos no desenvolvimento das forças produtivas que liberem o tempo para o usufruto da classe trabalhadora. Todas as formas de liberação de tempo no capitalismo estão, assim, direta ou indiretamente atreladas à valorização do capital.

Em termos marxianos, não se pode falar em tempo livre sem que toda a sociedade esteja implicada em exercer esse tempo ativamente, isto é, a produção material só atingiria esse estágio se o tempo livre estivesse posto socialmente e se tivesse como centro de sua libertação uma atividade fundamentalmente científica, oposta, nesse sentido, a todas as formas de adestramento, gerenciamento e subalternização características do trabalho de tipo assalariado.

Falar em tempo livre por ocasião do desenvolvimento das forças produtivas, como fundamento do indivíduo social, implica em estabelecer uma direção política que tenha como objetivo eliminar a lei do valor-trabalho, substituindo as formas de produção tipicamente capitalistas por formas comunistas de produção. ${ }^{12}$

A transformação de tempo de trabalho em tempo livre - na qual o desenvolvimento das forças produtivas abriria espaço para a constituição do indivíduo social - só se afina com a leitura de Marx em um momento em que a sociedade socialista se apresenta como norteadora desse movimento. Portanto, a liberação de tempo de trabalho no capitalismo, além de representar uma mistificação da relação de subordinação do trabalho em relação ao capital, tem, do ponto de vista da classe trabalhadora, apenas um sentido estritamente negativo, expresso nas mais atuais formas de subalternização do trabalho.

Abstract: The working time is a central concept to the Marxist analysis of capitalist society. From Karl Marx to the present day, the discussion on the reduction of working time has been developed by several interpretations. Among them is one that points to the gradual reduction of working time. Progressive, this case is not understood on the basis of its own contradiction, in other words, as a need of capital for their valorization, but as a process of progressive reduction of working time that, ultimately, put the capital relation in check. Based on this interpretation, the trend of reduction of working time would announce the extinction of capitalist relations of production. We would, therefore, faced with a perspective that is grounded in a social automatism and therefore assumes the end of capitalism in a deterministic way. Returning to the more central implications that the restructuring process, called toyotist, has provided, especially those relating to the massive replacement of workers by informational technology and microelectronic, this article aims to revisit the notion of working time, trying thereby to demonstrate the fragility of the thesis that assumes a structural breakdown of capitalist society as the result of an automatic internal movement of capital reproduction. We conclude that these theories in practice mystify the centrality of class struggle, first as a determinant element of the constitution of capitalist productive forces, and second, as an overcoming element for the subordination of labor to capital.
12. Entendemos aqui o socialismo como uma sociedade de transição e não como um modo de produção típico. Nesse sentido, o socialismo se sintetizaria pela progressiva constituição de relações sociais e forças produtivas comunistas e pela eliminação também progressiva das relações sociais capitalistas já subordinadas à ditadura do proletariado. Naves (1994: 72) sintetiza esse argumento da seguinte forma: "Após a revolução, a luta de classes prossegue, com a classe operária procurando, por um lado, destruir o núcleo duro das relações sociais capitalistas, justamente aquilo que permite a dominação e a expropriação do trabalhador: uma dada organização do processo de trabalho retira do operário todo e qualquer controle das condições materiais da produção e do produto de seu trabalho, e que se funda na divisão entre o trabalho manual e o trabalho intelectual, e na divisão entre as tarefas de direção e de execução. E, por outro lado, procurando destruir o aparelho de Estado burguês, visando, por meio da ditadura do proletariado, transformá-lo em algo que já não seja 
mais propriamente um Estado, isto é, procurando criar as condições para a sua extinção. O socialismo é precisamente esse período de transição do capitalismo para o comunismo no qual a classe operária luta para operar essas transformações na base econômica do capitalismo, e para se apropriar efetivamente - e não apenas formalmente - do poder."
Keywords: working time, social automatism, post-major industry, productive labor, unproductive labor, labor value.

\section{Referências}

Amorim, Henrique. Trabalho imaterial: Marx e o debate contemporâneo. São Paulo: Annablume, 2009.

. Valor-trabalho e imaterialidade da produção nas sociedades contemporâneas. Buenos Aires: Consejo Latino-Americano de Ciencias Sociales (Clacso), 2012.

ANTUNES, Ricardo. Riqueza e miséria do trabalho no Brasil II. São Paulo: Boitempo, 2013. . Riqueza e miséria do trabalho no Brasil. São Paulo: Boitempo, 2006.

BELL, Daniel. O advento da sociedade pós-industrial: uma tentativa de previsão social. São Paulo: Cultrix, 1973.

BRAVERMAN, Harry. Trabalho e capital monopolista: a degradação do trabalho no século XX. Rio de Janeiro: Zahar, 1980.

CASTElls, Manuel. A Era da Informação: economia, sociedade e cultura. In CASTELLS, Manuel. A sociedade em rede. São Paulo: Paz e Terra, 1999.

DAL Rosso, Sadi. Mais trabalho! A intensificação do labor na sociedade contemporânea. São Paulo: Boitempo, 2008.

DAL Rosso, Sadi; ForTeS, José Augusto Sá. Condições de trabalho no limiar do século XXI. Brasília: Época, 2008.

FAUsto, Ruy. A pós-grande indústria nos Grundrisse (e para além deles). Lua Nova, n. 19, 1989, p. 47-67.

GoRz, André. O imaterial: conhecimento, valor e capital. São Paulo: Annablume, 2005.

— . Adeus ao proletariado - Para além do socialismo. Rio de Janeiro: Forense, 1987.

GOULDNER, Alvin. El futuro de los intelectuales y el ascenso de la nueva clase. Madrid: Alianza Editorial, 1979.

HABERMAS, Jürgen. Teoría de la acción comunicativa. Madrid: Taurus, 1987.

Husson, M. Nouvelle économie: capitalisme toujours! Critique Comuniste, n. 159/160, eté/automne 2000. 
INGLEHART, Ronald. Modernization and postmodernization: cultural, economic, and political change in 43 societies. Princeton-NJ: Princeton University Press, 1997.

LOJKINE, Jean. A revolução informacional. São Paulo: Cortez, 1992.

MARX, Karl. Grundrisse: manuscritos econômicos de 1857-58: esboços da crítica da economia política. São Paulo: Boitempo, 2011 [1857-1858].

- Elementos fundamentales para la crítica de la economia política (Borrador). Buenos Aires: Siglo Veintiuno; Argentina Editores, 1972 [1857-1858].

— . O capital. São Paulo: Nova Cultural, 1988 [1867].

- Capítulo VI - Inédito de O capital: resultados do processo de produção imediata. São Paulo: Moraes, 1985.

MeluCCl, Alberto. The new social movements: a theoretical approach. Social Science Information, v. 19, n. 2, 1980.

Mıglıolı, Jorge. Marx e o colapso da União Soviética. Crítica Marxista, v. 1, n. 1, 1994, p. 61-63.

MoUlier-BOUTANG, Yann. Le capitalisme cognitif: la nouvelle grande transformation. Paris: Éditons Amsterdam, 2007.

NAVES, Márcio. Marxismo e capitalismo de Estado. Crítica Marxista, v. 1, n. 1, 1994, p. 71-74.

Negri, Antonio. Capitalisme cognitif et fin de l'économie politique. Multitudes, n. 13, 2003, p. 197-205.

NeGRI, Antonio; HARDT, Michael. Império. Rio de Janeiro: Record, 2001.

Nicolas-Le StRAT, Pascal. Travail e constitution du sens à propos d'André Gorz. Futur Antérieur, n. 35-36, 1996, p. 101-109.

Offe, Claus. Trabalho: a categoria-chave da Sociologia? Revista Brasileira de Ciências Sociais, v. 4, n. 10, Jun. 1989, p. 6-20.

_. Trabalho e sociedade. Rio de Janeiro: Tempo Brasileiro, 1989a.

PrAdo, Eleutério. Uma crítica à economia política do imaterial. Revista Outubro, n. 11, 2004, p. 45-70.

SAKAMOTO, Leonardo. Trabalho escravo no Brasil do século XXI. Brasília: Organização Internacional do Trabalho, 2006. 
- . Lucro fácil, mão de obra descartável, a escravidão contemporânea e economia internacional. In Coggıola, Osvaldo (Org.). América Latina e a globalização. São Paulo: Faculdade de Filosofia, Letras e Ciências Humanas/Programa de Pós-Graduação em Integração da América Latina da Universidade de São Paulo, 2004.

SCHAFF, Adam. A sociedade informática. São Paulo: Unesp;Brasiliense, 1992.

TOSEL, André. Centralité et non-centralité du travail ou la passion des hommes superflus. In BIDET, Jacques; TEXIER, Jaques (Orgs.). La crise du travail. Paris: Presses Universitaires de France, 1994, p. 209-218.

TOURAINE, Alain. Os novos conflitos sociais: para evitar mal-entendidos. Lua Nova, n.17, 1989, p. 5-18.

Sociedade pós-industrial. Lisboa: Moraes Editores, 1970.

VASAPOLLO, Luciano. O trabalho atípico e a precariedade. São Paulo: Expressão Popular, 2005.

VINCENT, Jean Marie. Os automatismos sociais e o "general intellect". Futur Antérieur, n. $16,1993 / 2$, p. 1-15.

VIVERET, Patrick. Reconsidérer la richesse. Paris: Éditions de l'Aube, 2003. 